\title{
Erratum to: Modeling preventive maintenance of manufacturing processes with probabilistic Boolean networks with interventions
}

\author{
Pedro J. Rivera Torres ${ }^{1}$ - Eileen I. Serrano Mercado ${ }^{2}$. Orestes Llanes Santiago ${ }^{3}$.
}

Luis Anido Rifón ${ }^{1}$

Published online: 3 April 2017

(C) Springer Science+Business Media New York 2017

\section{Erratum to: J Intell Manuf \\ DOI 10.1007/s10845-016-1226-x}

In Table 3 , the value presented on row 1, column 3 is missing a zero and is incorrect. The corrected version of Table 3 is published with this erratum.

Table 3 Pick and place's Bn vector functions, selection probabilities and attractors

\begin{tabular}{|c|c|c|c|}
\hline $\mathrm{BN}$ realization & Vector function & Selection probability & Attractors \\
\hline 1 & $f_{1}=\left(f_{1}^{(1)}, f_{1}^{(2)}, f_{1}^{(3)}\right)$ & 0.00031 & $(1,3,5,7,8)$ \\
\hline 2 & $f_{2}=\left(f_{1}^{(1)}, f_{1}^{(2)}, f_{2}^{(3)}\right)$ & 0.00426 & $(1,2,4,6,8)$ \\
\hline 3 & $f_{3}=\left(f_{1}^{(1)}, f_{2}^{(2)}, f_{1}^{(3)}\right)$ & 0.00426 & $(1,3,7,8)$ \\
\hline 4 & $f_{4}=\left(f_{1}^{(1)}, f_{2}^{(2)}, f_{2}^{(3)}\right)$ & 0.05879 & $(1,4,8)$ \\
\hline 5 & $f_{5}=\left(f_{2}^{(1)}, f_{1}^{(2)}, f_{1}^{(3)}\right)$ & 0.00426 & $(1,5,7,8)$ \\
\hline 6 & $f_{6}=\left(f_{2}^{(1)}, f_{1}^{(2)}, f_{2}^{(3)}\right)$ & 0.05879 & $(1,6.8)$ \\
\hline 7 & $f_{7}=\left(f_{2}^{(1)}, f_{2}^{(2)}, f_{1}^{(3)}\right)$ & 0.05879 & $(1,7,8)$ \\
\hline 8 & $f_{8}=\left(f_{2}^{(1)}, f_{2}^{(2)}, f_{2}^{(3)}\right)$ & 0.81073 & $(1,8)$ \\
\hline
\end{tabular}

The online version of the original article can be found under doi:10.1007/s10845-016-1226-x.

Pedro J. Rivera Torres

privera@ece.uprm.edu

1 ETSET-Universidade de Vigo, Campus Universitario, s/n, 36310 Vigo, Spain

2 Polytechnic University of Puerto Rico, 377 Ponce de León Ave., Hato Rey, PR, USA

3 Departamento de Automática y Computación, Instituto Superior Politécnico José A. Echevarría (CUJAE),

La Habana, Cuba 